ISSN 1991-8631

Original Paper

http://indexmedicus.afro.who.int

\title{
Extraction and characterization of chitin and chitosan from Nigerian shrimps
}

\author{
M. T. ISA ${ }^{1 *}$, A. O. AMEH ${ }^{1}$, M. TIJJANI ${ }^{1}$ and K. K. ADAMA ${ }^{2}$ \\ ${ }^{1}$ Department of Chemical Engineering, Ahmadu Bello University, Zaria, Nigeria. \\ ${ }^{2}$ Physics Advanced Laboratory, Sheda Science and Technology Complex (SHESTCO), Abuja, Nigeria. \\ *Corresponding author; E-mail: mtisaz@yahoo.com,mtisa@abu.edu.ng
}

\begin{abstract}
Chitin was synthesized from Nigerian brown shrimps by a chemical process involving demineralization and deproteinisation. Deacetylation of the chitin was conducted to obtain Chitosan. The chitin and chitosan were characterized using FTIR, XRD and SEM. Proximate and elemental analysis were also conducted. The percentage yield of chitin was $8.9 \%$. The degree of deacetylation of chitin was found to be $50.64 \%$ which was a low value compared to previous works and can be attributed to the low alkali concentration and heating time. XRD patterns indicated that chitin was more crystalline than the corresponding chitosan. FTIR spectra indicated the presence of functional groups associated with different bands, the intensities and stretching established that the samples are chitin and chitosan. SEM analysis also indicated morphological differences between the chitin and chitosan.
\end{abstract}

(C) 2012 International Formulae Group. All rights reserved.

Keywords: Deacetylation, biodegradable, characterization, deproteinisation, demineralization.

\section{INTRODUCTION}

Chitin is a white, hard, inelastic, nitrogenous polysaccharide, available from variety of sources which include, exoskeleton of crustaceans, cell wall of certain fungi, mushrooms, worms, diatoms, arthropods, nematodes and insects, with shellfish waste such as shrimps, crabs and crawfish being the principal sources (Muzzarelli, 1997; Nessa et al., 2010). Worldwide, chitin is the second most abundant and most important natural polysaccharide after cellulose. It is composed of $\beta$ (1 $\rightarrow 4$ )-linked 2-acetamido-2-deoxy- $\beta$-D- glucose (N-acetyl glucosamine (Dutta et al., 2004; Rinaudo, 2006).

There are many derivatives of chitin, these include, chitosan, $\mathrm{N}$-acetyl chitosan, monoacetyl chitin, dibutyrylchitin, chitosan acetate, etc (Jacek et al., 1990). The main derivative of chitin is chitosan a linear polymer of $\alpha(1 \rightarrow 4)$ linked 2-amino-2-deoxy$\beta$-D-glucopyranose and is easily derived by $\mathrm{N}$-deacetylation, to a varying degree that is characterized by the degree of deacetylation. This is consequently a copolymer of $\mathrm{N}$-acetyl glucosamine and glucosamine (Dutta et al., 2002; Aranaz et al., 2009). 
Chitin is estimated to be produced annually almost as much as cellulose. It has become of great interest not only as underutilized resource but also as a new functional biomaterial of high potential in various fields because of their unique biodegradability, biocompatibility, physiological inertness, nontoxicity, adsorption and hydrophilicity. Recently, progress of chitin chemistry has been quite significant (Hudson et al., 1998; Sashiwa and Aiba, 2004).

It has been reported that the potential and usual areas of application of chitin, chitosan and their derivatives are estimated to be more than 200 (Kumar, 2000). Some of the applications are in food processing, cosmetics, biomedical, biocatalysis and waste water treatment processes (Li et al., 1997; Bhavani and Dutta, 1999; Sridhari and Dutta, 2000). Chung et al. (2003) have shown that because of the natural antibacterial and/or antifungal characteristics, chitosan and its derivatives have resulted in their use in commercial disinfectant. Chu-his et al. (2001) treated effluent waste water from textile and diary industries and established that chitosan was a better treatment (decolorization) option than the activated carbon in use. Also chitosan works efficiently for effluents with both low and high $\mathrm{pH}$ values. These materials have also found wide application in conventional pharmaceutics as potential formulation excipient. Their use in novel drug delivery as mucoadhesive and as oral enhancer has also been reported (Kalut, 2008).

The isolation of chitin from different sources is affected by the source (Abdou et al., 2008). In the creatures where chitin is found, it is in different percentages depending on the place where it is obtained (Muzzarelli, 1997). Various methods have been reported for the extraction of chitin and converting it to chitosan. These include chemical, biological and thermal processes (Khanafari, et al., 2008; Abdou et al., 2008).

This work was aimed at the extraction of chitin and converting it into chitosan. The chitin is obtained from Nigerian brown shrimp which is abundant in the coastal areas of the country, with shells considered to constitute waste and pollute environment and aquatic life. Chemical method of extraction was adopted because of its simplicity.

\section{MATERIALS AND METHODS \\ Chitin extraction}

Chitin was extracted from $200 \mathrm{~g}$ of the shrimp shell by demineralising and deproteinising of the solid material after size reduction. Demineralization was carried out at room temperature using $1 \mathrm{M}$ hydrochloric acid $(\mathrm{HCl})$. Evolution of gas indicates the mineral content of the specie. The treatment was repeated several times until the evolution of gas ceased with 3 liters of the prepared $1 \mathrm{M}$ $\mathrm{HCl}$. The resulting shell was then washed with distilled water up to neutrality, dried in an oven at $60{ }^{\circ} \mathrm{C}$ until a constant weight was obtained. Deproteinisation was carried out by heating the shell at $100{ }^{\circ} \mathrm{C}$ in $1 \mathrm{M}$ sodium hydroxide solution. The treatment was repeated several times, the absence of colour indicates the absence of protein a total of 1.5 liters of the solution was used. Washing with distilled water was then carried out up to neutrality and then dried at $60{ }^{\circ} \mathrm{C}$ until constant weight was achieved to obtain chitin.

\section{Deacetylation of chitin}

Chitosan was obtained by the removal of acetyl group (deacetylation) in the chitin structure. This was achieved by steeping (soaking) the chitin sample in strong sodium hydroxide $(40 \% \mathrm{w} / \mathrm{w})$ solution for four days to degrade the chitin. The sample was then heated in a fresh alkaline solution at $100{ }^{\circ} \mathrm{C}$ 
and at atmospheric pressure for $5 \mathrm{hrs}$ to obtain chitosan.

\section{Proximate analysis}

Proximate analysis of the chitin and chitosan was carried out to determine moisture content, ash content, protein and fibre content. The samples were dried to a constant weight at $60{ }^{\circ} \mathrm{C}$ in an oven and the weight loss gives the amount of moisture in the samples. Samples were burned in a furnace at temperature of $555^{\circ} \mathrm{C}$ and weighed to determine the ash content. The fibre and protein content were determined by standard method (AOAC, 1990).

\section{Carbon/Nitrogen ratio determination}

The organic carbon content analysis was carried out in the nitrogen laboratory Institute of Agricultural Research ( IAR Ahmadu Bello University, Zaria) using the Walkley-black method. The organic nitrogen content was also determined using Kjekdahl method. The carbon/nitrogen ratio will be used in determining the degree of deacetylation of the chitosan sample using the Kasaai equation (Abdou et al., 2008)

$\mathrm{DDA} \%=\frac{6.857-C / N}{1.7143}$ 1

\section{Structural analysis}

The X-ray diffraction of the samples was conducted using PAN analytical X' Pert PRO MPD X-ray diffraction system PW3040/60 machine. The prepared samples were prepared and held on a sample holder and beams of electron passed through. The intensity was measured at Bragg's $2 \theta$ angle. The Crystallinity of the chitin and chitosan samples was determined from $X$ - ray diffraction analysis. The structural differences of the chitin and chitosan samples were also established via Fourier transform infrared spectroscopy using FTIR-8400S spectrophotometer (Shimadzu) machine. The morphology of the chitin and chitosan samples were visualised using a scanning electron microscope (JEOL 6400). The samples were thinly coated with gold and transferred to the sample holder and the micrographs were taken.

\section{RESULTS}

\section{Percentage composition of shell}

After the demineralization and the deproteinisation of the shrimp shells, the percentage composition of the shells was calculated. This is presented in Table 1.

\section{Elemental analysis of chitosan}

Table 2 presents the degree of deacetylation calculated using Kasaai "Equation (1)" after the deacetylation of the chitin.

\section{Proximate analysis of chitin and chitosan}

Table 3 presents the results of the proximate analysis of the chitin and chitosan.

\section{X-ray diffraction analysis of samples}

Figures 1 presents the supper imposed diffraction patterns of the chitin and chitosan respectively.

\section{Morphology of chitin and chitosan}

Figures 2 and 3 present the scanning electron micrographs of the chitin and chitosan.

\section{FTIR spectroscopy analysis}

Figures 4 and 5 present the Fourier transform infra red spectroscopy of the chitin and chitosan samples. 


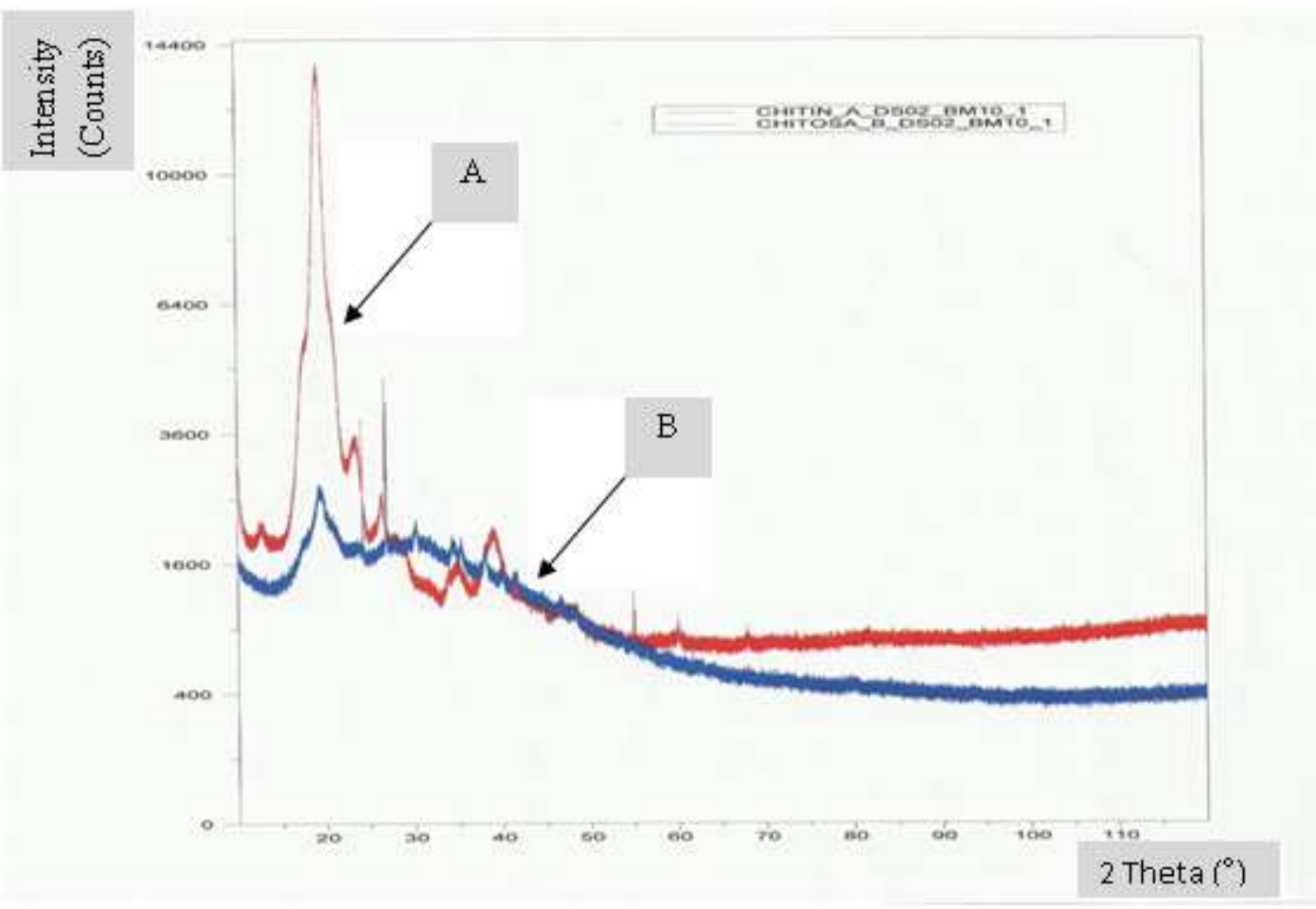

Figure 1: Superimposed X-ray diffraction patterns of chitin (A) and chitosan (B).

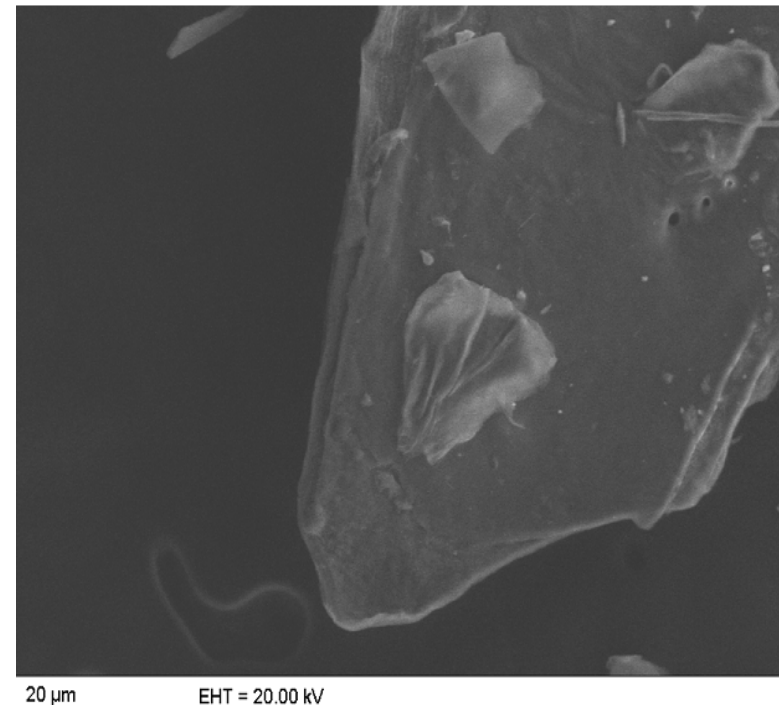

Figure 2: Scanning electron micrograph of chitin.

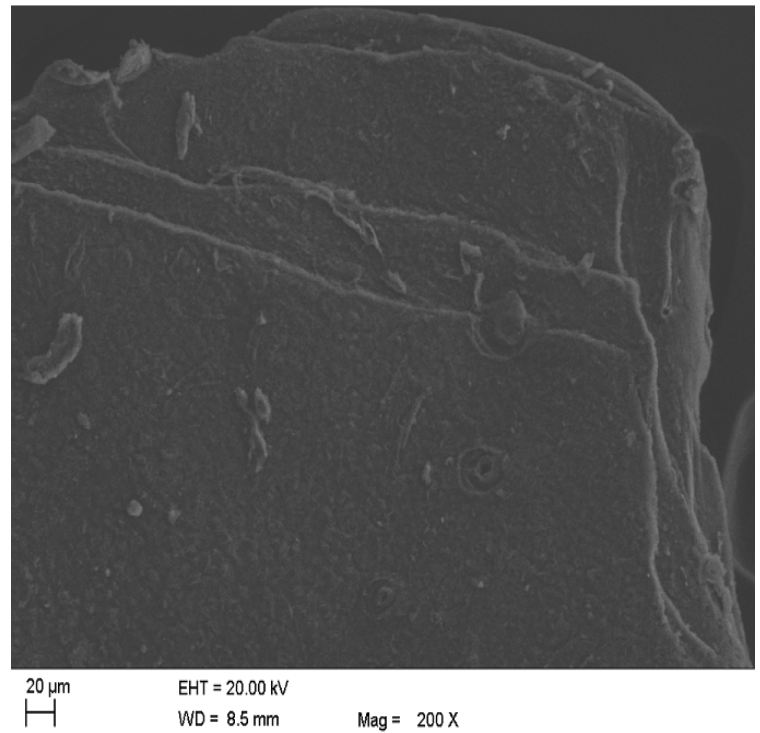

Figure 3: Scanning electron micrograph of chitosan. 


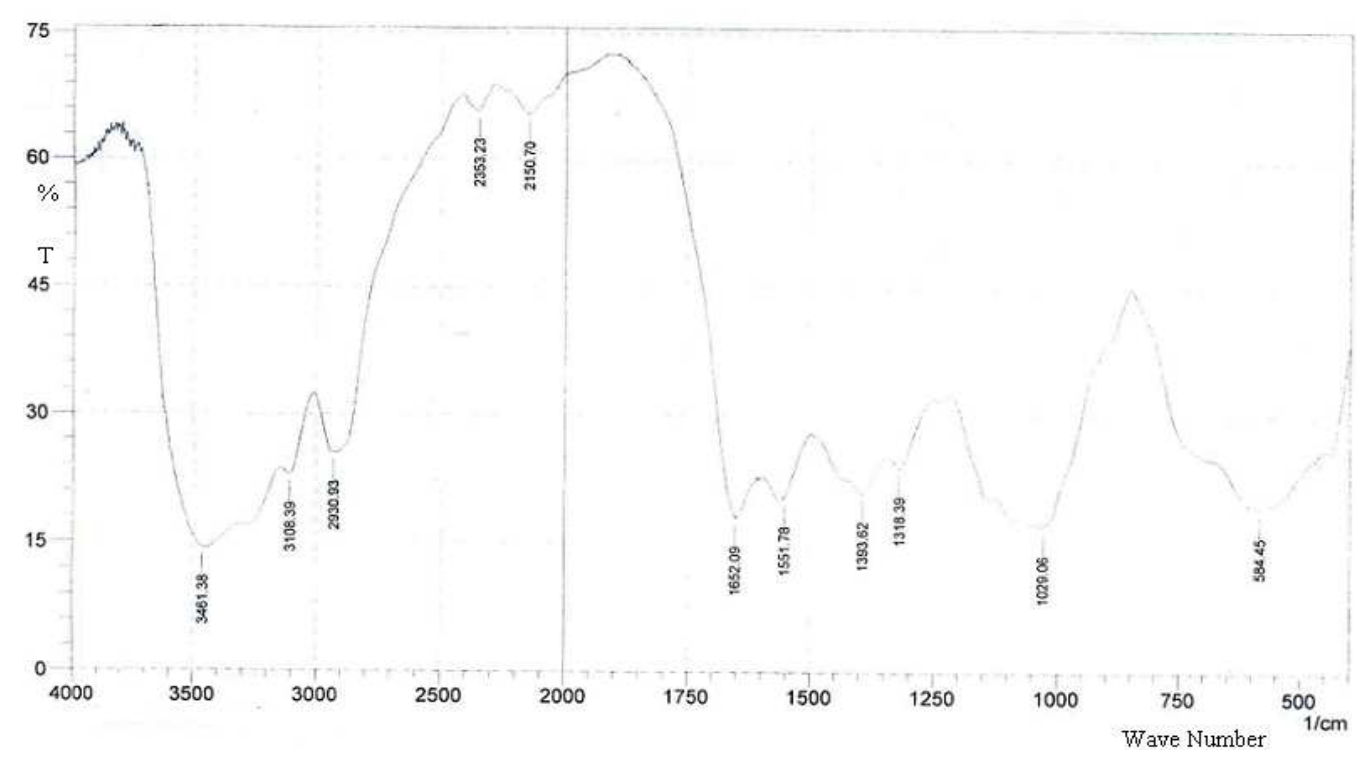

Figure 4: FTIR spectra of chitin.

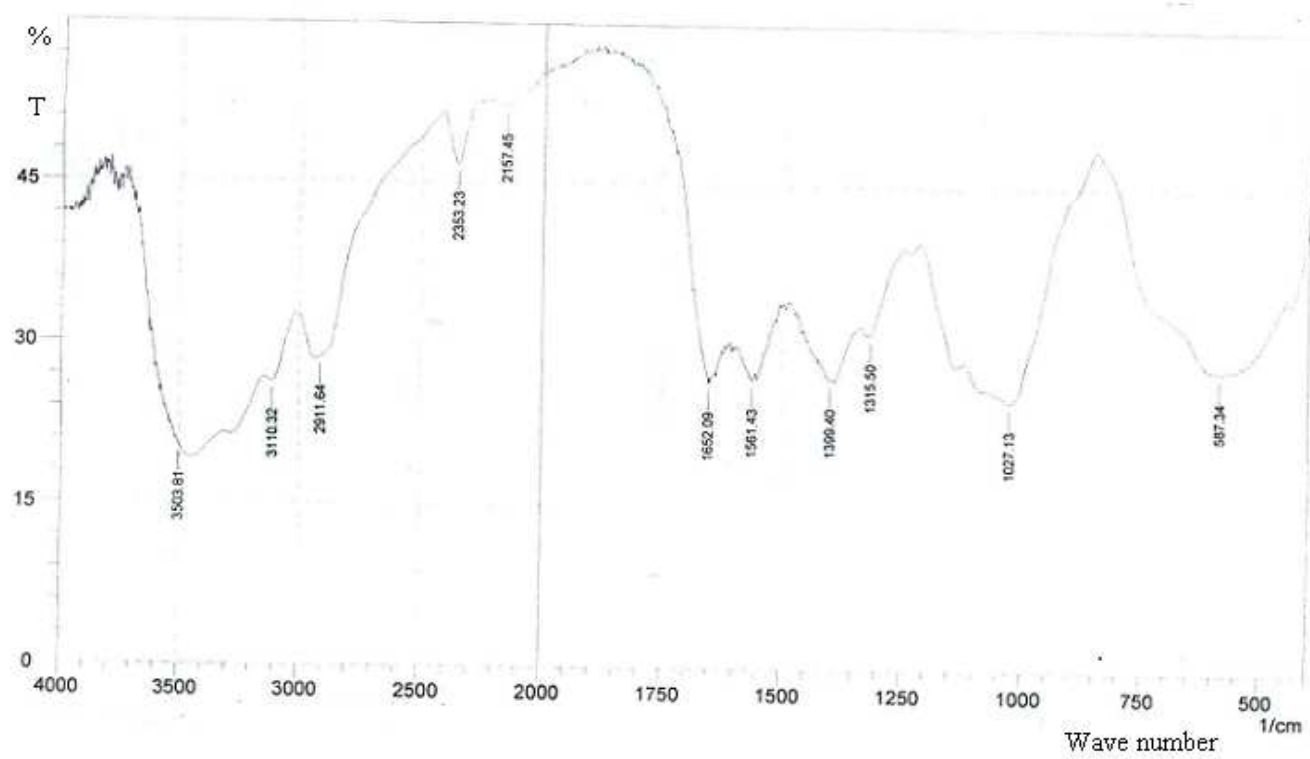

Figure 5: FTIR spectra of chitosan.

Table 1: Shrimp shell composition.

\begin{tabular}{ll}
\hline Component & \% Composition \\
\hline $\mathrm{CaCO}_{3}$ & 69.7 \\
Protein & 21.4 \\
Chitin & 8.9 \\
\hline
\end{tabular}


Table 2: Nitrogen and Carbon content analysis of chitosan.

\begin{tabular}{lcll}
\hline Nitrogen (\%) & Carbon (\%) & Carbon/nitrogen ratio & Degree of Deacetylation (\%) \\
\hline 2.71 & 16.23 & 5.989 & 50.64 \\
\hline
\end{tabular}

Table 3: Proximate analysis of chitin and chitosan.

\begin{tabular}{lllll}
\hline Material & Moisture (\%) & Ash (\%) & Protein (\%) & Fibre (\%) \\
\hline Chitin & 9.40 & 3.83 & 10.50 & 4.10 \\
Chitosan & 5.24 & 6.41 & 6.16 & 8.74 \\
\hline
\end{tabular}

\section{DISCUSSION}

\section{Percentage composition of shell}

The shrimp was found to contain low amount of chitin, $8.9 \%$ (Table 1) compared to $21.53 \%$ recorded by Abdou et al. (2008), this may be attributed to the mineral composition of the area as composition varies with the area of the retrieved source. As mentioned earlier, the isolation of chitin from different sources is affected by the source (Abdou et al., 2008), also in the creatures where chitin is found, it is in different percentages depending on the place (Muzzarelli, 1997).

\section{Elemental analysis of chitosan}

As indicated in Table 2 the chitosan produced contains high amount of organic carbon but with low organic nitrogen content. This result was used to determine the degree of deacetylation (DDA). The degree of deacetylation was approximately $51 \%$ which is considered low compared to previously reported work where DDA of $87-97 \%$ was achieved at different deacetylation conditions (Abdou et al., 2008) and 98.38-98.79\% achieved by Kalut (2008). The low DDA in this work could be attributed to the conditions (alkali concentration, pressure and non pulverisation of chitin) used for the deacetylation. Extended heating time and high alkali concentration can be applied to drastically improve the degree of deacetylation. The results also confirm that low carbon/nitrogen ratio yields higher degree of deacetylation which is desired. The product obtained after deacetylation of the chitin was partially soluble in dilute acetic acid, as DDA of $60 \%$ was expected for complete solubility in dilute acetic acid. However, 100\% solubility was obtained in concentrated acetic acid.

As indicated in Table 3, the moisture content of chitin was found to be higher than the corresponding chitosan which was expected since water was removed from the chitin prior to the production of chitosan.

Ash content of chitin was lower than that of chitosan this could be attributed to the presence of the acetyl group in the chitin sample. It is worth noting that ash is the inorganic residue remaining after water and organic matter have been removed from a sample.

Protein content of the chitosan sample was considered high after deproteinisation of the chitn and this could be attributed to the low degree of deacetylation of the chitin.

It was also found that the fibre content of the chitosan was higher than that of chitin, probably the removal of more matter from the chitin to get chitosan could have led to the presence of more fibre in the chitosan than chitin.

\section{X-ray diffraction analysis of samples}

The most intense peak height for the chitin sample was recorded at $2 \theta=20^{\circ}$ with a spacing of $4.25946 \AA$ as shown in Figure 1 (A). A decrease in peak and increase in broadness is observed for chitosan sample in 
Figure 1(B). The broad peaks indicate lower crystallinity; this is to say that chitin is more crystalline than chitosan, which is similar to the observation reported in literature (AlSagheer et al., 2009).

\section{Morphology of chitin and chitosan}

The scanning electron micrographs of the chitin and chitosan revealed that chitin has a smoother surface than chitosan as can be seen in Figures 2 and 3. The rough surface of the chitosan is attributed to the low degree of deacetylation (Abdel-Fattah et al., 2007). The chitosan showed prominent sheath-like layers than the chitin, this could probably be as result of deacetylation of the chitin which removes some bonding agents and exposing more sheaths in the chitosan.

\section{FTIR spectroscopy analysis}

From Figure 4, the chitin showed peak at $1551.78 \mathrm{~cm}^{-1}$ which corresponds to the N-H deformation of amide II. The band at 1652.09 $\mathrm{cm}^{-1}$ corresponds to the amide I stretching of $\mathrm{C}=\mathrm{O}$. The band at $1393.62 \mathrm{~cm}^{-1}$ corresponds to a symmetrical deformation of the $\mathrm{CH}_{3}$ group (Duarte et al., 2001; Ravindra et al., 1998).

The spectra of Figure 5 correspond to the deacetylated sample with $\mathrm{NaOH}$. Note that for chitosan, the band at $1551.78 \mathrm{~cm}^{-1}$ has a bit larger intensity than at $1652.09 \mathrm{~cm}^{-1}$, which suggests some degree of deacetylation of the chitin. When chitin deacetylation occurs, the band observed at $1652.09 \mathrm{~cm}^{-1}$ decreases, while a growth at $1551.78 \mathrm{~cm}^{-1}$ occurs, indicating the prevalence of $\mathrm{NH}_{2}$ groups (Bordi et al., 1991).

\section{Conclusion}

Chitin was extracted from Nigerian brown shrimp. The deacetylation of the obtained chitin was conducted using chemical method. It was found that the shrimp had $8.8 \%$ of chitin, and the degree of deacetylation was $50.64 \%$.

The difference in structure and surface morphology of the chitin and product (chitosan) obtained from the deacetylation of chitin was established through the use of FTIR, SEM and XRD. The XRD analysis indicated that the chitin was more crystalline than the chitosan.

Further work can be done to improve on the degree of deacetylation probably through size reduction of the chitin, increase in concentrations of the reagents, reaction time and increase in temperature of deacetylation as suggested by literature.

\section{REFERENCES}

Abdel- Fattah WI, Jiang T, El-Bassyouni GE, Laureuci CT. 2007. Synthesis, characterization of chitosans and fabrication of sintered chitosan microsphere matrices for bone tissue engineering. Acta Biomaterial, 3(4): 503514.

Abdou ES, Nagy KSA, Elsabee MZ. 2008. Extraction and characterization of chitin and chitosan from local sources. Biresources Technology, 99: 1359-1367.

Al- Sagheer FA, Al- Sughayer MA, Muslim S, Elsabee MZ. 2009. Extraction and characterization of chitin and chitosan from marine sources in Arabian Gulf. Carbohydrate Polymers, 77(2): 410-419.

AOAC. 1990. Official Methods of Analysis $\left(15^{\text {th }}\right.$ edn). Association of Official Analytical Chemists: Washington, DC, 1990

Aranaz I, Mengibar M, Harris R, Panos I, Miralles B, Acota N, Galed G, Heras A. 2009. Functional characterization of chitin and chitosan. Current Chemical Biology, 3: 203-230.

Bhavani KD, Dutta PK. 1999. Physicochemical adsorption properties on chitosan for dye house effluent. Am. Dyestuff. Rep., 88: 53.

Bordi F, Cametti C, Paradossi G. 1999. Dielectric behaviour of polyelectrolyte solutions: the role of proton fluctuations. J. Phy. Chem., 95: 4883-4889.

Chung YC, Wang HL, Chen YM, Li SL. 2003. Effect of abiotic factors on the 
antibacterial activity of chitosan against water borne pathogens. Bioresources Techonology, 88: 179-184.

Chu-shi H, Jui-lien H, Rong-huei C. 2008. Wastewater treatment with chitosan. available at www. Edoc.ypu.edu.tw: 8080/paper/HMST/2008. Accessed May 2011.

Duarte ML, Ferreira MC, Marvao MR, Rocha J. 2001. Determination of the degree of actylation of chitin materials ${ }^{13} \mathrm{C}$ CP/MAS NMR spectroscopy. Int. Biol. Mac. Mol., 28: 359-363.

Dutta PK, Ravikumar MNV, Dutta J. 2002. Chitin and chitosan for versatile applications. JMS Polym. Rev., C42: 307.

Dutta PK, Dutta J, Tripathi VS. 2004. Chitin and chitosan: Chemistry, properties and applications. J. Sc. Ind. Res., 63: 20-31.

Hudson SM, Smith C. 1998. Polysaccharide: Chitin and chitosan: chemistry and technology of their use as structural materials. In Biopolymer from Renewable Resources, Kaplan DL (ed). SpringerVerlag: New York, 96-118.

Jacek D, Lidia S, Magdalena K, Luba J, Ryszard C. 1990. Structure - Bioactivity relationship of chitin derivatives -Part I: The effect of solid chitin derivatives on blood coagulation. J. Bioactive Polymers, 5(3): 293-304.

Kalut SA. 2008. Enhancement of degree of deacetylation of chitin in chitosan production. B. Chemical Engineering, Universiti Malaysia Pahang, 2.

Khanafari A, Marandi R, Sanatei S. 2008. Recovery of chitin and chitosan from shrimp waste by chemical and microbial method. Iran. J. Environ. Health Sci. Eng., 5( 1): 19-24.

Kumar MNVR. 2000. A review of chitin and chitosan applications. React Funct Polym., 46: 1-27.

Li Q, Dunn ET, Grandmaison EW, Goosen MFA. 1997. Applications and properties of chitosan. In Applications of chitin and chitosan, Goosen MFA (ed). Technomic Publishing Company: Lancaster; 3-29.

Muzzarelli RAA. 1997. Some modified chitosan and their niche applications. In Chitin Handbook, Muzzarelli RAA, Peter MG (eds). European Chitin Society: Italy, 47-52.

Nessa F, Shah MM, Asaduzzaman M, Roy SK, Hossain MM, Jahan MS. 2010. A process for the preparation of chitin and chitosan from prawn shell waste. Bangladesh J. Sci. Ind. Res., 45(4): 323330.

Ravindra R, Krovvidi KR, Khan AA. 1998. Solubility parameter of chitin and chitosan. Carbohydrate Polymers., 55: 17-22.

Rinaudo M. 2006. Chitin and chitosan. Prog. Polym..,31: 603-632.

Sashiwa H, Aiba SI. 2004. Chemically modified chitin and chitosan as biomaterials. Prog. Polym. Sci., 29: 887908.

Sridhari TR, Dutta PK. 2000. Synthesis and characterization of maleilated chitosan for dye house effluent. Indian J. Chem. Tech., 7: 198. 